\title{
Surgical safety of cervical pedicle screw placement with computer navigation system
}

\author{
Nobuyuki Shimokawa ${ }^{1} \cdot$ Toshihiro Takami $^{2}$ \\ Received: 16 February 2016 / Revised: 30 April 2016 / Accepted: 19 May 2016/Published online: 31 May 2016 \\ (C) The Author(s) 2016. This article is published with open access at Springerlink.com
}

\begin{abstract}
Cervical pedicle screw (CPS) may be the biomechanically best system for posterior cervical segmental fixation, but may carry a surgery-related risk. The purpose of this study was to evaluate the safety of CPS placement using computer navigation system for posterior cervical instrumented fixation and discuss its complication avoidance and management. Posterior cervical instrumented fixation using CPS was performed in a total of 128 patients during the period between 2007 and 2015. Intraoperative image guidance was achieved using a preoperative 3D CT-based or an intraoperative 3D CTbased navigation system. A total of 762 CPSs were placed in the spine level of $\mathrm{C} 2$ to $\mathrm{Th} 3$. The radiological accuracy of CPS placement was evaluated using postoperative CT. Accuracy of CPS placement using a preoperative 3D CT-based navigation system was $93.6 \%$ (423 of 452 screws) in grade 0 ; the screw was completely contained in the pedicle, and accuracy of CPS placement using an intraoperative 3D CT-based navigation system was a little bit improved to $97.1 \%$ (301 of 310 screws) in grade 0 . CPS misplacement (more than half of screw) was $3.3 \%$ (15 of 452 screws) using a preoperative 3D CT-based navigation system, and CPS misplacement (more than half of screw) was $0.6 \%$ ( 2 of 310 screws) using an intraoperative 3D CT-based navigation system. In total, 38 screws $(5.0 \%)$ were found to perforate the cortex of pedicle, although any neural or vascular complications closely associated with CPS placement were not encountered. Twenty nine of 38 screws
\end{abstract}

Nobuyuki Shimokawa

nobu-shimo0215@snow.odn.ne.jp

1 Department of Neurosurgery, Tsukazaki Hospital, 68-1 Waku, Aboshi-ku, Himeji, Hyogo, Japan

2 Department of Neurosurgery, Osaka City University Graduate School of Medicine, Osaka, Japan
(76.3\%) were found to perforate laterally, and seven screws (18.4\%) were found to perforate medially. Image-guided CPS placement has been an important advancement to secure the safe surgery, although the use of CPS placement needs to be carefully determined based on the individual pathology.

Keywords Cervical spine · Image-guided surgery · Pedicle screw $\cdot$ Posterior cervical fixation $\cdot$ Spinal instrumentation

\section{Introduction}

Posterior cervical instrumented fixation has undergone revolutionary changes over the last several decades, since posterior cervical stabilization using lateral mass screw (LMS) was first described by Roy-Camille et al. in 1979 [1]. Various surgical techniques of interlaminar wiring, LMS, transarticular screw, and most recently, cervical pedicle screw (CPS), are available [2-9]. Successful clinical application of CPS for traumatic cervical injury was first reported by Abumi et al. [1], and posterior cervical instrumented fixation using CPS is gaining popularity and can be applied for cervical spine injury and for several cervical pathological conditions, such as cervical spondylotic myelopathy (CSM) with instability, kyphotic deformity, congenital anomaly, or neoplastic destruction. CPS may be the best biomechanical system for posterior segmental fixation [10-15], but may also carry a surgery-related risk of neural or vascular complications [3, 16-19]. On the other hand, the popularization of posterior cervical instrumented fixation has raised an important issue of safe surgical management. The purpose of this study was to evaluate the accuracy of CPS placement using computer navigation system for posterior cervical instrumented fixation and discuss its complication avoidance and management. 
Table 1 Patient characteristics

\begin{tabular}{ll}
\hline Characteristics & No. (range) \\
\hline Total no. of patients & 128 \\
Sex (male/female) & $84 / 44$ \\
Mean age at surgery (years) & $65.5(15-92)$ \\
Postoperative follow-up (months) & $51.8(6-121)$ \\
Preoperative diagnosis & \\
CSM with instability & 50 \\
Trauma & 35 \\
Reducible cervical kyphosis & 13 \\
CSM associated with athetoid-type cerebral palsy & 11 \\
DSA & 5 \\
Anomaly & 4 \\
Tumor & 4 \\
RA & 4 \\
Infection & 2 \\
\hline
\end{tabular}

$C S M$ cervical spondylotic myelopathy, $D S A$ destructive spondyloarthropathy, $R A$ rheumatoid arthritis

\section{Material and methods}

\section{Patient population}

Posterior cervical instrumented fixation of the occipitocervical, cervical, or cervicothoracic spine using CPS combined with/without LMS was performed in 128 patients at our institute between 2007 and 2015. The patients included 84 men and 44 women, and the mean age at surgery was 65.5 years (range, 1592 years). The clinical diagnosis was CSM with instability in 50 patients, trauma in 35 patients, reducible cervical kyphosis in 13 patients, CSM associated with athetoid-type cerebral palsy in 11 patients, destructive spondyloarthropathy (DSA) in 5 patients, rheumatoid arthritis (RA) in 4 patients, congenital anomaly in 4 patients, neoplastic destruction in 4 patients, and infection in 2 patients. The patient characteristics are summarized in Table 1.

\section{Preoperative evaluation}

Comprehensive radiological evaluation was routinely accomplished. Pedicle morphology (coronal and axial, sagittal) and the medial inclination of the pedicle axis were carefully evaluated. CPS was not indicated is cases with a pedicle diameter less than $4 \mathrm{~mm}$, as determined by preoperative 3D CT imaging. The development and running course of the vertebral artery (VA) in the transverse foramen at each vertebra, and the collateral vascular network (i.e., posterior communicating arteries) were carefully evaluated with MR angiography and/ or CT angiography. When occlusion of the unilateral VA was recognized before surgery, CPS was avoided on the remaining side. In such cases, CPS in the VA occluded side and LMS in the remaining side were performed (Fig. 1a, b).

\section{Surgical procedure}

CPSs were placed using a preoperative 3D CT-based navigation system (Stealth Station and Stealth Station TREON ${ }^{\mathrm{TM}}$, Medtronic, Inc., Memphis, TN, USA) during the first study period (2007-2012) and using an intraoperative 3D CT-based navigation system (O-arm and Stealth Station 7, Medtronic, Inc., Memphis, TN, USA) during the second study period (2012-2015). After standard exposure of the posterior cervical spine, CPSs were basically placed before the decompressive procedure such as laminoplasty or laminectomy. In the early series of a preoperative 3D CT-based navigation system, navigation frame was fixed to the spinous process of the vertebra where CPSs were placed. The accuracy of navigation was carefully adjusted by using the method of point registration and surface matching (separate registration), especially in case
Fig. 1 a Selection of cervical pedicle screw (CPS) and lateral mass screw (LMS) in cases in which preoperative MR angiography shows occlusion of the vertebral artery on the right side. b Postoperative CT shows that CPS was placed on the right side and the LMS on the left side
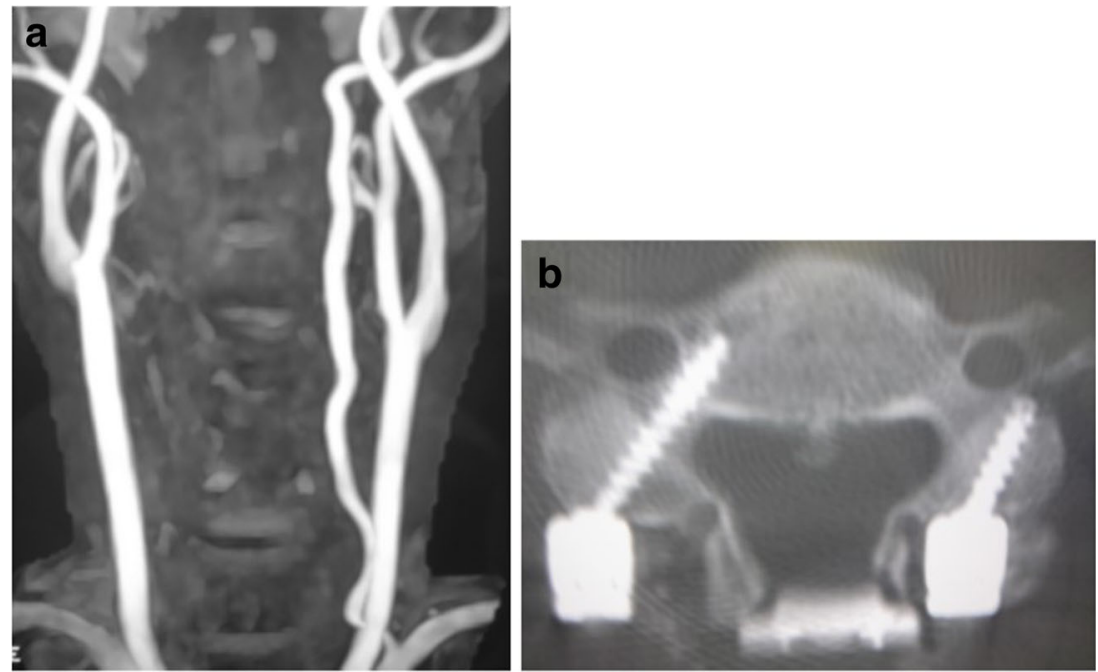
of the unstable cervical spine. The CPS insertion point was prepared using a 2-mm diamond burr. The screw hole was then dug gently using a navigation straight probe. The ballpoint sounder probe was used to make sure that the cortex of pedicle was not violated, and finally, the CPS was inserted under the guidance of lateral fluoroscopy. Navigation accuracy was repeatedly confirmed by touching the anatomical landmark of the posterior cervical spine before another CPS insertion. Even in the latter series of an intraoperative 3D CT-based navigation system, the accuracy of navigation was repeatedly confirmed within two above-two below vertebral levels at one fixed registration frame. In case of long fixation, the range of navigation registration was divided into several segments of four or five vertebral levels.

The axial trajectory of CPS is often restricted or pressed medially by the surrounding paravertebral muscles (Fig. 2a). The stronger the axial trajectory is kept against the medial

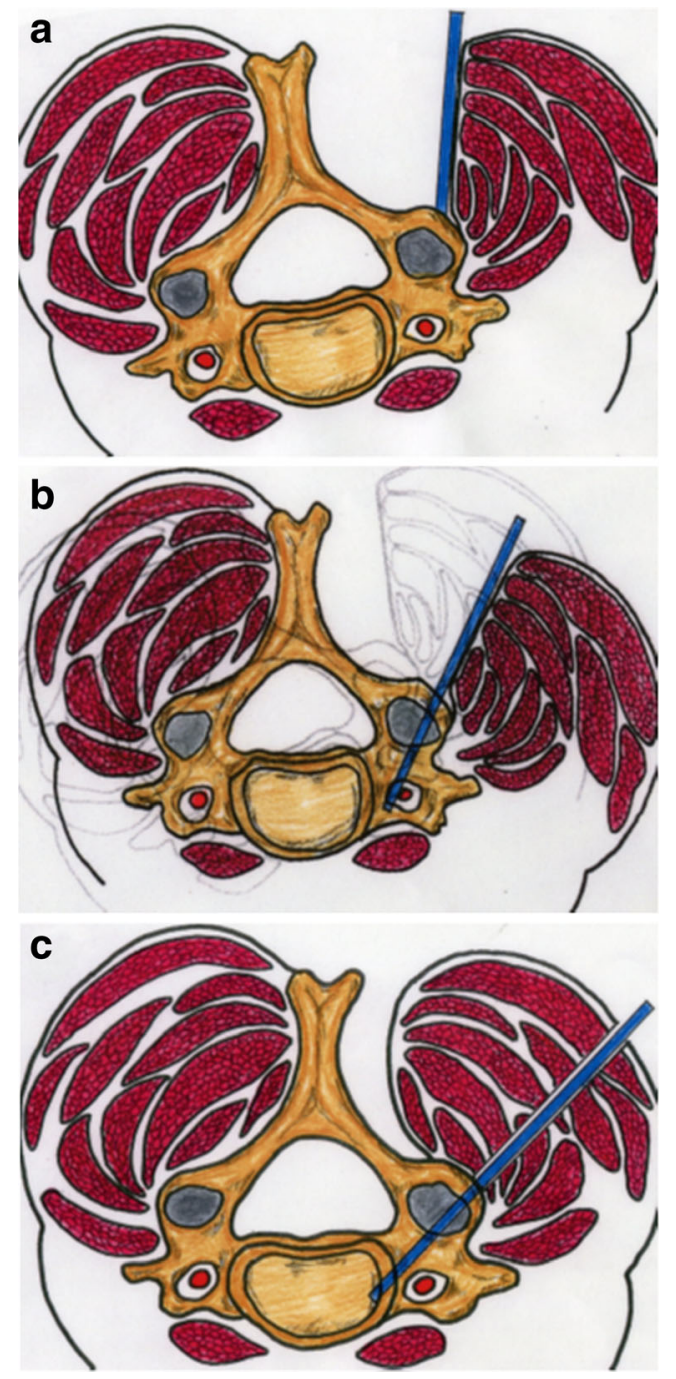

Fig. 2 Illustrations showing that the axial trajectory of CPS is often restricted or pressed medially by the surrounding paravertebral muscles (a), and screws may be misplaced laterally (b). Percutaneous placement of CPS was a choice to resolve such a technical problem (c) pressure from the paravertebral muscles, the easier axial rotation or sagittal bending of the cervical spine might be, so that screws may be misplaced laterally (Fig. 2b). There might be a higher risk of VA injury. When extreme oblique trajectory of CPS through posterior midline approach was disturbed by the cervical paravertebral muscles, percutaneous placement of CPS was a choice to resolve such a technical problem (Fig. 2c).

After placement of CPSs, laminectomy or laminoplasty was performed if necessary. However, in cases of severe canal stenosis, such as combined or beak-type OPLL with instability, a decompression procedure was considered before CPS placement. CPSs were tightly connected using a rod system with/without spinal correction. In cases of neural foraminal stenosis, there is a risk of iatrogenic nerve root impingement due to worsening of foraminal stenosis that may be caused by a corrective reduction procedure. Excessive compression force at the segments was avoided in such cases. Finally, autologous local bone with beta tricalcium phosphate (TCP) was placed into the posterior surface of decorticated facet joints on both sides. After setting the screw-rod contouring, cervical alignment and correct position of all CPSs was confirmed using lateral fluoroscopy or intraoperative 3D CT with an Oarm.

\section{Statement of ethics}

This is a retrospective case analysis. We certify that all applicable institutional and governmental regulations concerning the ethical use of clinical data were followed in the present study. Patient informed consent was obtained prior to surgery.

\section{Results}

The radiological accuracy of CPS placement was evaluated using postoperative $\mathrm{CT}$ scans and was defined retrospectively by a grading scale originally proposed by $\mathrm{Neo}$ et al. [20]. (Fig. 3). Screw positions were classified into four grades: grade 0 , no perforation, and the screw was completely contained in the pedicle; grade 1 , perforation $<2 \mathrm{~mm}$ (that is, less than half of the screw diameter); grade 2 , perforations $\geq 2 \mathrm{~mm}$ but $<4 \mathrm{~mm}$; and grade 3 , perforation $\geq 4 \mathrm{~mm}$ (complete perforation). A total of 452 CPSs were placed using a preoperative 3D CT-based navigation system (first period of 20072012), and a total of 310 CPSs using an intraoperative 3D CTbased navigation system (second period of 2012-2015), so that 762 CPSs were placed in the spine level of $\mathrm{C} 2$ to $\mathrm{Th} 3$. In the first period of 2007-2012, accuracy of CPS placement was $93.6 \%$ (423 of the 452 screws) in grade $0,3.1 \%$ (14 of the 452 screws) in grade $1,2.7 \%$ (12 of the 452 screws) in grade 2 , and $0.6 \%$ (3 of the 452 screws) in grade 3 . In the second period of 2012-2015, accuracy of CPS placement was 


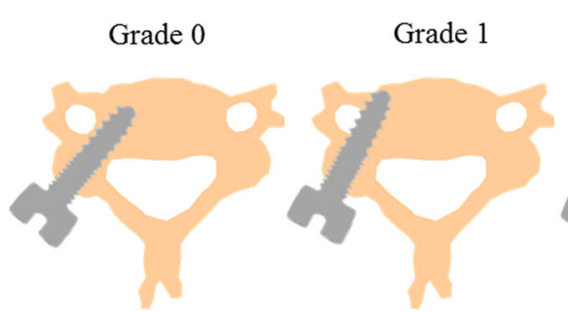

Grade 2

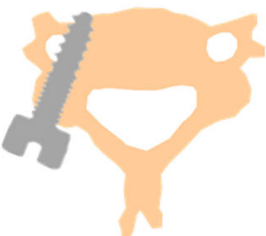

Grade 3

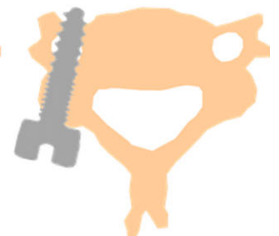

Fig. 3 Illustrations showing the grading scale of the radiological accuracy of CPS placement evaluated using postoperative CT scan that was originally proposed by Neo et al. [14]

$97.1 \%$ (301 of the 310 screws) in grade $0,2.3 \%$ ( 7 of the 310 screws) in grade $1,0.3 \%$ (1 of the 310 screws) in grade 2 , and $0.3 \%$ ( 1 of the 310 screws) in grade 3 . Accuracy of CPS placement was also analyzed based on spine level. Screw malposition was found $0.9 \%$ (1 of 114 screws) at C2, $5.5 \%$ (5 of 91 screws) at $\mathrm{C} 3,5.9 \%$ (8 of 135 screws) at C4, $4.9 \%$ (6 of 122 screws) at C5, $3.3 \%$ (3 of 88 screws) at C6, $10.2 \%$ (10 of 98 screws) at C7, $5.9 \%$ (4 of 68 screws) at T1, $2.9 \%$ (1 of 34 screws) at T2, and $0 \%$ (0 of 12 screws) at T3. The overall rate of screw malposition rate at C2-C6 (where VAs are usually running in the transverse foramen) was $4.1 \%$ (23 of 550 screws). Illustrative case of posterior cervical instrumented fixation using CPS was presented in Figs. 4 and 5

In total, 38 of the 762 screws $(5.0 \%)$ were found to perforate the cortex of pedicle in the first and second period, although any neural or vascular complications closely associated with CPS placement were not encountered in the present study. There was no case of vertebral artery injury related to CPS placement. Twenty nine of the 38 screws $(76.3 \%)$ were found to perforate laterally, 7 screws $(18.4 \%)$ were found to perforate medially, and 2 screws $(5.3 \%)$ were found to perforate inferiorly. There were no screws that were found to perforate superiorly. Accuracy of CPS placement was summarized in Table 2.

\section{Discussion}

In the present study, we focused our attention on the safe CPS placement for posterior cervical instrumented fixation. Careful imaging analysis demonstrated that a total of 38 of the 762 screws $(5.0 \%)$ were found to perforate the cortex of pedicle in the first and second period, although any neural or vascular complications closely associated with CPS placement were not encountered. CPS misplacement was more recognized in C7 compared to the other spine level, and the misplacement to lateral direction tended to occur in midlower cervical spine. CPS at C7 is usually applied in case of posterior cervical long fusion, and placed at the caudal side of fusion segment. The procedure of CPS placement at C7 level may be easily affected by the inward pressure of welldeveloped paravertebral muscle layers. The stronger the axial trajectory is kept against the medial pressure from the paravertebral muscles, the easier the axial rotation or sagittal bending of the cervical spine might be, so that screws may be misplaced laterally. The accuracy of CPS placement may be also affected by anatomical complexity of cervical pedicle or navigation error.

In 1991, Panjabi et al. published the first three-dimensional anatomical study of the human cervical vertebrae [21]. The three-dimensional coordinates of various marked points on the surface of the vertebra were measured with a specially designed morphometer instrument. Transverse pedicle diameter increased from $5.1 \mathrm{~mm}$ at $\mathrm{C} 3$ to $6.6 \mathrm{~mm}$ at $\mathrm{C} 7$, and sagittal diameter increased from 6.7 to $7.6 \mathrm{~mm}$ across the same levels. Karaikovic et al. investigated cervical pedicle morphology using human cadaver specimens via manual and computed tomography measurements and suggested that there were anatomical limitations associated with the use of the pedicle screw in the cervical spine [22, 23]. Chazono et al. evaluated the linear and angular parameters of the cervical spine as well as pedicle dimensions required for safe CPS placement using multiplanar CT reconstruction [24]. They reported that the overall mean pedicle transverse angle (PTA) ranged from 33.6 to $50.2^{\circ}$ and that the smallest mean PTA was found at
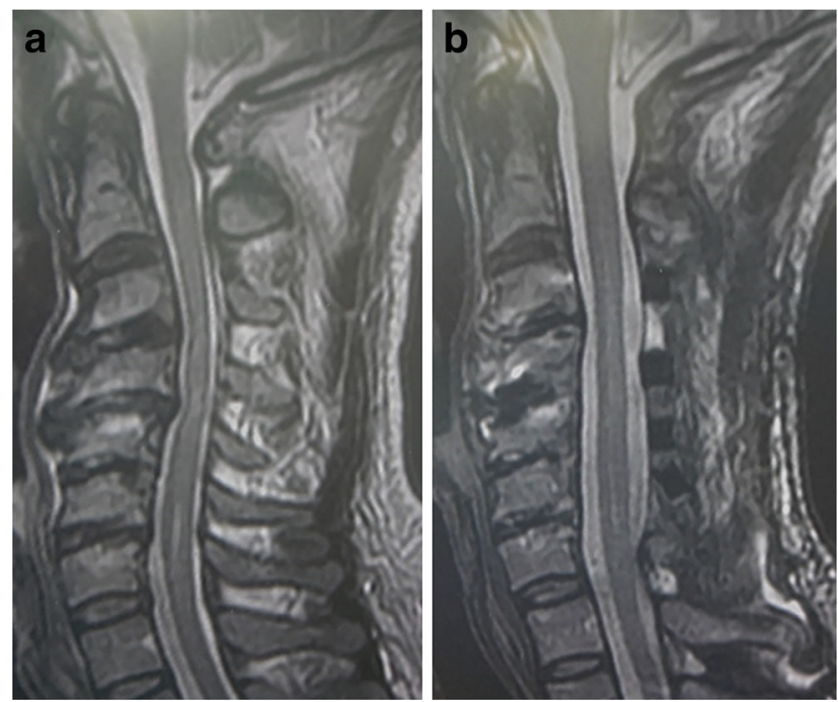

Fig. 4 Illustrative case. A 47-year-old man presented with gradually progressive tetraparesis. He underwent posterior decompressive and corrective fixation using C2-T2 CPSs combined with anterior fusion. a. Preoperative MRI revealing cervical kyphosis resulting in cervical spondylotic myeopathy. b. Postoperative MRI 
Fig. 5 Illustrative case. The same patient in Fig. 4. a Postoperative plain cervical radiograph. b-i Postoperative axial CT scans at spine level from $\mathrm{C} 2$ to $\mathrm{Th} 2$
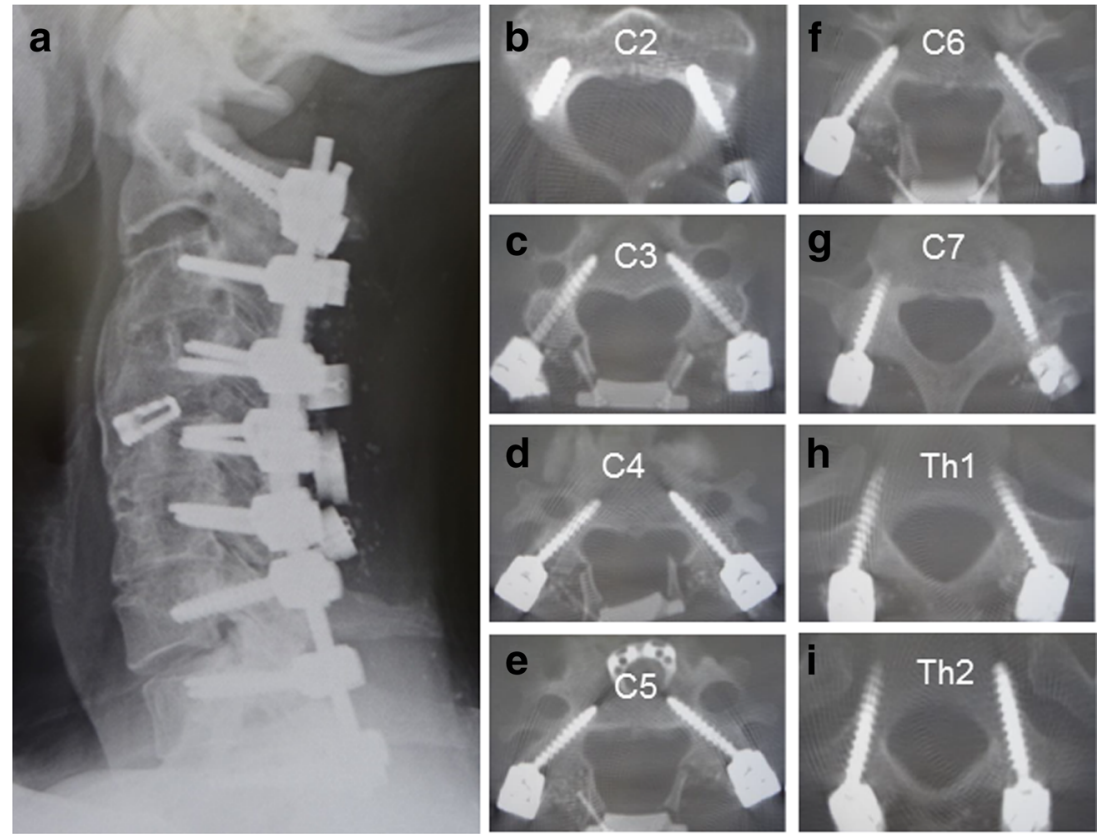

$\mathrm{C} 7$ in males $\left(33.4^{\circ}\right)$ and in females $\left(34.1^{\circ}\right)$; the largest mean PTA was found at $\mathrm{C} 4$ in males $\left(50.4^{\circ}\right)$ and in females $\left(49.6^{\circ}\right)$ followed by $\mathrm{C} 5, \mathrm{C} 3$, and $\mathrm{C} 6$. Further, the pedicle sagittal angle (PSA) varied from $13.7^{\circ}$ in the cephalad direction at $\mathrm{C} 3,5.3^{\circ}$ at $\mathrm{C} 4,1.3^{\circ}$ caudally at $\mathrm{C} 5,3.0^{\circ}$ caudally at $\mathrm{C} 6$, and $3.3^{\circ}$ caudally at $\mathrm{C} 7$. The suggested that not only pedicle dimensions but also linear and angular parameters of the cervical vertebral body can be useful data for safe CPS placement. Wang et al. demonstrate their technique of free-hand subaxial CPS placement without using intraoperative navigation devices, and reported clinical results in which $\mathrm{C} 3$ showed a higher perforation rate than the other vertebrae [25]. They analyzed the transverse angle of CPS trajectory and perforation of the lateral wall by using postoperative CT scans, and suggested that there are two crucial maneuvers for increasing accuracy of screw placement: identifying the precise entry point and guiding CPS trajectory on axial plane by the resistant of thick medial wall. Shin et al. reported that the pedicle size and angle as well as the shapes of the cervical pedicle are important for safe CPS insertion [26]. Twenty-six human cervical vertebrae from fresh-frozen spines were secured to a thin sectioning apparatus to produce three $0.7-\mathrm{mm}$-thick pedicle slices along its axis. Radiographs taken of these pedicle slices were scanned, digitized, and traced to facilitate visual comparison. The pedicle slices were found to exhibit substantial variability in composition and shape, not only between individual spines and vertebral levels but also within the pedicle axis. They suggested that the lateral cortex was consistently found

Table 2 Accuracy of CPS placement

\begin{tabular}{|c|c|c|c|c|c|c|c|c|c|c|}
\hline \multirow[t]{2}{*}{ Spinal level } & \multirow[t]{2}{*}{ No. of CPSs } & \multirow[t]{2}{*}{ Grade 0} & \multirow[t]{2}{*}{ Grade 1} & \multirow[t]{2}{*}{ Grade 2} & \multirow[t]{2}{*}{ Grade 3} & \multirow[t]{2}{*}{ Grade $1-3(\%)$} & \multicolumn{4}{|c|}{ CPS misplacement } \\
\hline & & & & & & & Medially & Laterally & Inferiorly & Superiorly \\
\hline $\mathrm{C} 2$ & 114 & 113 & 0 & 0 & 1 & 0.9 & 1 & 0 & 0 & 0 \\
\hline $\mathrm{C} 3$ & 91 & 86 & 4 & 1 & 0 & 5.5 & 1 & 4 & 0 & 0 \\
\hline $\mathrm{C} 4$ & 135 & 127 & 5 & 3 & 0 & 5.9 & 2 & 6 & 0 & 0 \\
\hline $\mathrm{C} 5$ & 122 & 116 & 4 & 2 & 0 & 4.9 & 1 & 5 & 0 & 0 \\
\hline C6 & 88 & 85 & 2 & 1 & 0 & 3.3 & 0 & 2 & 1 & 0 \\
\hline $\mathrm{C} 7$ & 98 & 88 & 3 & 5 & 2 & 10.2 & 0 & 9 & 1 & 0 \\
\hline $\mathrm{T} 1$ & 68 & 64 & 3 & 0 & 1 & 5.9 & 0 & 4 & 0 & 0 \\
\hline $\mathrm{T} 2$ & 34 & 33 & 1 & 0 & 0 & 2.9 & 0 & 1 & 0 & 0 \\
\hline $\mathrm{T} 3$ & 12 & 12 & 0 & 0 & 0 & 0 & 0 & 0 & 0 & 0 \\
\hline Total & 762 & 724 & 22 & 12 & 4 & 5.0 & 7 & 29 & 2 & 0 \\
\hline
\end{tabular}

CPS cervical pedicle screw 
to be thinner than the medial cortex in all samples. They reported that pedicle axial slices in the mid-cervical vertebra exhibit a semi-circular or rectangular or triangular shape, with the flat surface directed towards the lateral aspect of each pedicle. As the slices progress antero-posteriorly along the pedicle long axis, the shape of the pedicle slices changes to a more circular conformation. Surprisingly, there are some slices that exhibited an unusual hook shape at their inferior aspects. These anatomical findings must be noted by surgeons attempting CPS placement for posterior cervical instrumented fixation.

The percentage of CPS misplacement varies from 2.5 to $29.1 \%$ in the literature (Table 3) [3, 16, 20, 27-36]. In the present study, $6.4 \%$ of CPS misplacement of grade 1-3 in the first period and $2.9 \%$ in the second period were recognized. Intraoperative image guidance is an important issue to avoid the surgery-related complications. Abumi et al. reported that 45 of 669 inserted screws $(6.7 \%)$ were misplaced in his early series [3]. Neo et al. reported that the rate of malposition was $29 \%$ in patients with degenerative conditions [20]. Hojo et al. reported that the overall rate of malposition was 158 of 1065 inserted screws $(14.8 \%)$ in their retrospective multicenter study of freehand insertion technique with fluoroscopy [16]. Even with a preoperative 3D CT-based navigation system, there is always a risk of misplacement of CPS that may result in significant neural or vascular complications. Intervertebral anatomical relationships with the patient in the prone position during surgery might not match the preoperative CT data obtained while the patient was in the supine position. This discrepancy has led to navigation errors. Intraoperative 3D CT-based navigation system may be the solution for navigation errors. It can reduce the discrepancy so that it may provide greater accuracy and feasibility during CPS placement. Ito et al. reported a malpositioning rate of $2.8 \%$ (5 of 176 screws) for CPS placement using a 3D fluoroscopy-based navigation system (Iso- $\mathrm{C}^{3 \mathrm{D}} \mathrm{C}$-arm, Siemens Medical Solutions, Erlangen, Germany) [29]. Ishikawa et al. also reported that a 3D fluoroscopy-based navigation system can improve the accuracy of CPS when compared with a conventional insertion technique [27]. Intraoperative 3D CTbased navigation system is the cutting edge of image-guided surgery that includes the acquisition of high-resolution images with $3 \mathrm{D}$ data during the surgery and enables surgeons to use them as fully automatic navigation. Although the quality of O-arm images may not be fully comparable to the images of multidetector helical CT, particularly at the cervicothoracic junction which is crucial for CPS, surgeons
Table 3 Review of the literature focusing on accuracy of CPS placement

\begin{tabular}{|c|c|c|c|c|c|c|}
\hline \multirow[t]{2}{*}{ Author } & \multirow[t]{2}{*}{ Year } & \multirow[t]{2}{*}{$\begin{array}{l}\text { No. of } \\
\text { patients }\end{array}$} & \multirow[t]{2}{*}{$\begin{array}{l}\text { No. of } \\
\text { CPSs }\end{array}$} & \multicolumn{2}{|c|}{$\begin{array}{l}\text { CPS } \\
\text { malposition }\end{array}$} & \multirow[t]{2}{*}{ Intraoperative image guidance } \\
\hline & & & & No. & $\%$ & \\
\hline Abumi et al. & 2000 & 180 & 667 & 45 & 6.7 & Fluoroscopy \\
\hline Kotani et al. & 2003 & 17 & 78 & 1 & 1.2 & $\begin{array}{l}\text { Preoperative CT-based (Kotani } \\
\text { probe) }\end{array}$ \\
\hline Neo et al. & 2005 & 18 & 86 & 25 & 29.1 & Fluoroscopy \\
\hline \multirow[t]{2}{*}{ Richter et al. } & \multirow[t]{2}{*}{2005} & 20 & 93 & 8 & 8.6 & Preoperative CT-based \\
\hline & & 32 & 167 & 5 & 3 & $\begin{array}{l}\text { Preoperative CT-based + cannulated } \\
\text { screw }\end{array}$ \\
\hline Ito et al. & 2008 & 50 & 176 & 5 & 2.8 & 3D fluoroscopy-based \\
\hline Yukawa et al. & 2009 & 144 & 417 & 59 & 14.3 & Fluoroscopy \\
\hline $\begin{array}{l}\text { Miyamoto } \\
\text { et al. }\end{array}$ & 2009 & 29 & 130 & 5 & 3.8 & CT cutout technique \\
\hline \multirow[t]{2}{*}{ Ishikawa et al. } & \multirow[t]{2}{*}{2010} & 30 & 126 & 34 & 27 & Fluoroscopy \\
\hline & & 32 & 150 & 28 & 18.7 & 3D fluoroscopy-based \\
\hline Ishikawa et al. & 2011 & 21 & 108 & 12 & 11.1 & Intaoperative CT-based \\
\hline $\begin{array}{l}\text { Kawaguchi } \\
\text { et al. }\end{array}$ & 2012 & 11 & 44 & 2 & 4.5 & Template system \\
\hline Tauchi et al. & 2013 & 46 & 196 & 24 & 12.2 & Preoperative CT-based \\
\hline Hojo et al. & 2014 & 283 & 1065 & 158 & 14.8 & Fluoroscopy \\
\hline Uehara et al. & 2014 & 129 & 579 & 116 & 20 & Preoperative CT-based \\
\hline $\begin{array}{l}\text { Kaneyama } \\
\text { et al. }\end{array}$ & 2015 & 20 & 80 & 2 & 2.5 & Template system \\
\hline \multirow[t]{2}{*}{ Present study } & & 89 & 452 & 29 & 6.4 & Preoperative CT-based \\
\hline & & 39 & 310 & 9 & 2.9 & Intaoperative CT-based \\
\hline
\end{tabular}


may not need to rely on the preoperative CT images in which the patient's position may vary from the surgical position during surgery.

CPS misplacement of grade 2 and grade 3 is clinically most critical. CPS misplacement of grade 2 and grade 3 in the present study was $3.3 \%$ (15 of the 452 screws) using a preoperative 3D CT-based navigation system, and CPS misplacement of grade 2 and grade 3 was $0.6 \%$ ( 2 of the 310 screws) using an intraoperative 3D CT-based navigation system. This advancement in image-guided surgery can improve the accuracy of CPS placement to secure the safe surgery. Lateral fluoroscopy in addition to computer navigation was also crucial and used for the accurate guidance of CPS placement, especially in case of high cervical or mid-cervical spine. However, in case of lower cervical or upper thoracic spine, CPS placement was basically guided only by using navigation, not lateral fluoroscopy, because the patient's shoulder or scapula may disturb the surgeons to see the direction of CPS clearly. Additionally, several technical considerations without navigation system must be discussed. Abumi et al. originally demonstrated his original technique to create a funnel-likeshaped hole at the screw insertion point down to the entrance of the pedicle to secure a wider range of freedom for the screw insertion angle $[2,37]$. Yukawa et al. used pedicle axis views generated by fluoroscopy during CPS placement [36]. Miyamoto et al. described a CT cutout technique to navigate the direction of the pedicle [32]. Recently, a patient-specific screw guide template system has been also introduced [30, 38].

\section{Conclusion}

The use of CPS placement for posterior instrumented fixation needs to be carefully determined based on the individual pathological and anatomical condition. A thorough knowledge of surgical anatomy, biomechanics, and technique remains the most essential aspect for successful surgery. Various attempts to avoid misplacement of CPS were performed but have not been completely successful. Therefore, we should continue to attempt to minimize the malposition rate by using a variety of techniques. Image-guided CPS placement has been an important advancement to avoid the surgery-related complications.

Acknowledgment The authors are deeply indebted to their alumni members for their great contributions to the present study.

Open Access This article is distributed under the terms of the Creative Commons Attribution 4.0 International License (http:// creativecommons.org/licenses/by/4.0/), which permits unrestricted use, distribution, and reproduction in any medium, provided you give appropriate credit to the original author(s) and the source, provide a link to the Creative Commons license, and indicate if changes were made.

\section{References}

1. Roy-Camille R, Gaillant G, Bertreaux D (1979) Early management of spinal injuries. In: McKibben B (ed) Recent advances in orthopedics. Edinburgh, Churchill-Livingstone, pp 57-87

2. Abumi K, Ito H, Taneichi H, Kaneda K (1994) Transpedicular screw fixation for traumatic lesions of the middle and lower cervical spine: description of the techniques and preliminary report. J Spinal Disord 7:17-28

3. Abumi K, Shono Y, Ito M, Taneichi H, Kotani Y, Kaneda K (2000) Complications of pedicle screw fixation in reconstructive surgery of the cervical spine. Spine 25:962-969

4. An HS, Gordin R, Renner K (1991) Anatomic considerations for plate screw fixation of the cervical spine. Spine 16:548-551

5. Anderson PA, Henley MB, Grady MS, Montesano PX, Winn HR (1991) Posterior cervical arthrodesis with AO reconstruction plates and bone graft. Spine 16(3 suppl):S72-S79

6. Coe JD, Vaccaro AR, Dailey AT, Skolasky RL, Sasso RC, Luwig SC, Dettori JR (2013) Lateral mass screw fixation in the cervical spine. J Bone Joint Surg Am 95:2136-2143

7. Jeanneret B, Gebhard JS, Magerl F (1994) Transpedicular screw fixation of articular mass fracture-separation: results of an anatomical study and operative technique. J Spinal Disord 7(1):222-229

8. Jeanneret B, Magerl F, Ward EH, Ward JC (1991) Posterior stabilization of the cervical spine with hook plates. Spine 16(3 Suppl): S56-S63

9. Miller RM, Ebraheim NA, Xu R, Yeasting RA (1996) Anatomic consideration of transpedicular screw placement in the cervical spine: an analysis of two approaches. Spine 21:2317-2322

10. Dunlap BJ, Karaikovic EE, Park HS, Sokolowski MJ, Zhang LQ (2010) Load sharing properties of cervical pedicle screw-rod constructs versus lateral mass screw-rod constructs. Eur Spine J 19: 803-808

11. Ito Z, Higashino K, Kato S, Kim SS, Wong E, Yoshida K, Hutton WC (2014) Pedicle screws can be 4 times stronger than lateral mass screws for insertion in the midcervical spine. J Spinal Disord Tech 27(2):80-85

12. Johnston TL, Karaikovic EE, Lautenschlagar EP, Marcu D (2006) Cervical pedicle screws vs. lateral mass screws: uniplanar fatigue analysis and residual pullout strengths. Spine J 6:667-672

13. Jones EL, Heller JG, Silcox DH, Hutton WC (1997) Cervical pedicle screws versus lateral mass screws. Anatomic feasibility and biomechanical comparison. Spine 22(9):977-982

14. Kotani Y, Cunningham BW, Abumi K, McAfee PC (1994) Biomechanical analysis of cervical stabilization systems: an assessment of transpedicular screw fixation in the cervical spine. Spine 19:2529-2539

15. Kothe R, Ruther W, Schneider E, Linke B (2004) Biomechanical analysis of transpedicular screw fixation in the subaxial cervical spine. Spine 29(17):1869-1875

16. Hojo Y, Ito M, Suda K, Oda I, Yoshimoto H, Abumi K (2014) A multicenter study on accuracy and complications of freehand placement of cervical pedicle screws under lateral fluoroscopy in different pathological conditions: CT-based evaluation of more than 1000 screws. Eur Spine J 23:2166-2174

17. Nakashima H, Yukawa Y, Imagama S, Kanemura T, Kamiya M, Yanase M, Ito K, Machino M, Yoshida G, Ishikawa Y, Matsuyama Y, Ishiguro N, Kato F (2012) Complications of cervical pedicle screw fixation for nontraumatic lesions: a multicenter study of 84 patients. J Neurosurg Spine 16:238-247

18. Onishi E, Sekkimoto Y, Fukumitsu R, Yamagata S, Matsushita M (2010) Cerebral infarction due to an embolism after cervical pedicle screw fixation. Spine 35(2):E63-E66 
19. Yoshihara H, Passias PG, Errico TJ (2013) Screw-related complications in the subaxial cervical spine with the use of lateral mass versus cervical pedicle screws. J Neurosurg Spine 19:614-623

20. Neo M, Sakamoto T, Fujibayashi S, Nakamura T (2005) The clinical risk of vertebral artery injury from cervical pedicle screws inserted in degenerative vertebrae. Spine 30(24):2800-2805

21. Panjabi MM, Duranccau J, Goel V, Oxland T, Takata K (1991) Cervical human vertebrae: quantitative three-dimensional anatomy of the middle and lower regions. Spine 16:861-869

22. Karaikovic EE, Daubs MD, Madsen RW, Gaines RW (1997) Morphologic characteristics of human cervical pedicles. Spine 22: 493-500

23. Karaikovic EE, Kunakornsawat S, Daubs MD, Madsen TW, Gaines RW (2000) Surgical anatomy of the cervical pedicles: landmarks for posterior cervical pedicle entrance location. J Spinal Disord 13:63-72

24. Chazono M, Soshi S, Inoue T, Kida Y, Ushiku C (2006) Anatomical considerations for cervical pedicle screw insertion: the use of multiplanar computerized tomography reconstruction measurements. J Neurosurg Spine 4:472-477, 2006

25. Wang Y, Xie J, Yang Z, Ahao Z, Zhang Y, Li T, Liu L (2013) Computed tomography assessment of lateral pedicle wall perforation by free-hand subaxial cervical pedicle screw placement. Arch Orthop Trauma Surg 133:901-909

26. Shin EK, Panjabi MM, Chen NC, Wang JL (2000) The anatomic variability of human cervical pedicles: considerations for transpedicular screw fixation in the middle and lower cervical spine. Eur Spine J 9:61-66

27. Ishikawa Y, Kanemura T, Yoshida G, Ito Z, Muramoto A, Ohno S (2010) Clinical accuracy of three-dimensional fluoroscopy-based computer-assisted cervical pedicle screw placement: a retrospective comparative study of conventional versus computer-assisted cervical pedicle screw placement. J Neurosurg Spine 13:606-611

28. Ishikawa Y, Kanemura T, Yoshida G, Matsumoto A, Ito Z, Tauchi R, Muramoto A, Ohno S, Nishimura Y (2011) Intraoperative, fullrotation, three-dimensional image (O-arm)-based navigation system for cervical pedicle screw insertion. J Neurosurg Spine 15:472-478
29. Ito Y, Sugimoto Y, Tomioka M, Hasegawa Y, Nakago K, Yagata Y (2008) Clinical accuracy of 3D fluoroscopy-assisted cervical pedicle screw insertion. J Neurosurg Spine 9:450-453

30. Kawaguchi Y, Nakano M, Yasuda T, Seki S, Hori T, Kimura T (2012) Development of a new technique for pedicle screw and Magerl screw insertion using a 3-dimensional image guide. Spine 37(23):1983-1988

31. Kotani Y, Abumi K, Ito M, Minami A (2003) Improved accuracy of computer-assisted cervical pedicle screw insertion. J Neurosurg 99(3 suppl):257-263

32. Miyamoto H, Uno K (2009) Cervical pedicle screw insertion using a computed tomography cutout technique. J Neurosurg Spine 11: 681-687

33. Richter M, Cakir B, Schmidt R (2005) Cervical pedicle screws: conventional versus computer-assisted placement of cannulated screws. Spine 30(20):2280-2287

34. Tauchi R, Imagama S, Sakai Y, Ito Z, Ando K, Muramoto A, Matsui H, Matsumoto T, Ishiguro N (2013) The correlation between cervical range of motion and misplacement of cervical pedicle screws during cervical posterior spinal fixation surgery using a CT-based navigation system. Eur Spine J 22:1504-1508

35. Uehara M, Takahashi J, Ikegami S, Mukaiyama K, Kuraishi S, Shimizu M, Futatsugi T, Ogihara N, Hashidate H, Hirabayashi H, Kato H (2014) Screw perforation features in 129 consecutive patients performed computer-guided cervical pedicle screw insertion. Eur Spine J 23:2189-2195

36. Yukawa Y, Kato F, Ito K, Horie Y, Hida T, Nakasima H, Machino M (2009) Placement and complications of cervical pedicle screws in 144 cervical trauma patients using pedicle axis view techniques by fluoroscope. Eur Spine J 18:1293-1299

37. Abumi K (2015) Cervical spondylotic myelopathy: posterior decompression and pedicle screw fixation. Eur Spine J 24:S186-S196

38. Kaneyama S, Sugawara T, Sumi M (2015) Safe and accurate midcervical pedicle screw insertion procedure with the patientspecific screw guide template system. Spine 40(6):E341-348 